\title{
nhalt / Contents 11/03
}

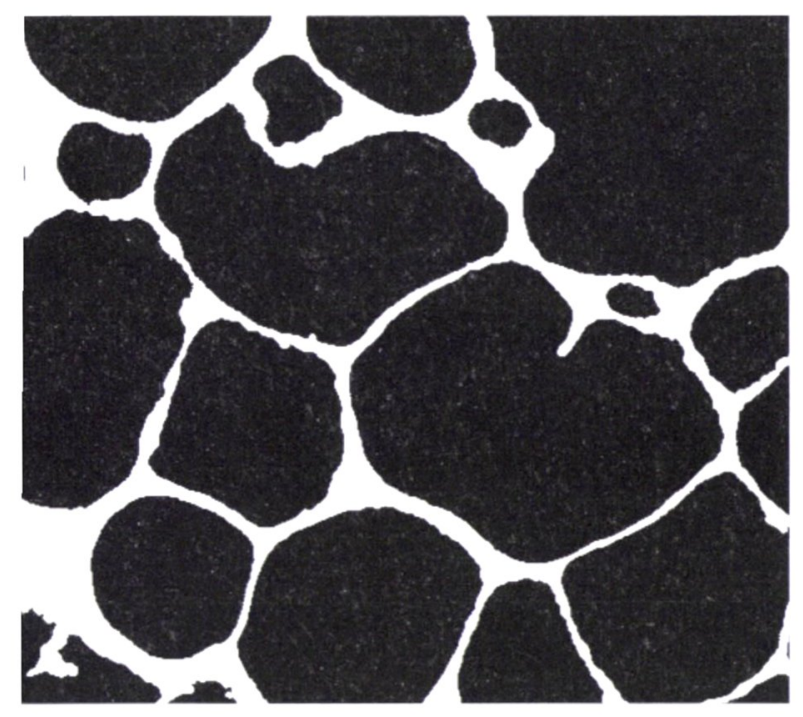

\section{B.Kriszt, K.Faure}

Charakterisierung der Zellstruktur von metallischen Schäumen

Characterisation of the Cell Structure of Metallic Foams

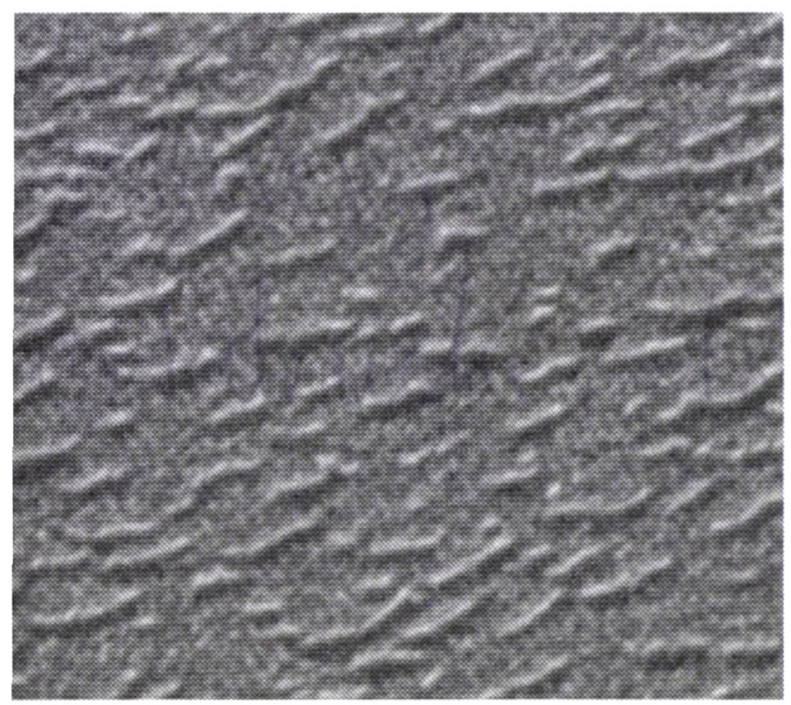

\section{Eduardo A. Favret, Néstor O. Fuentes}

RIMAPS Detection of Underlying Topography

RIMAPS - Detektierung einer zugrunde liegenden Topographie

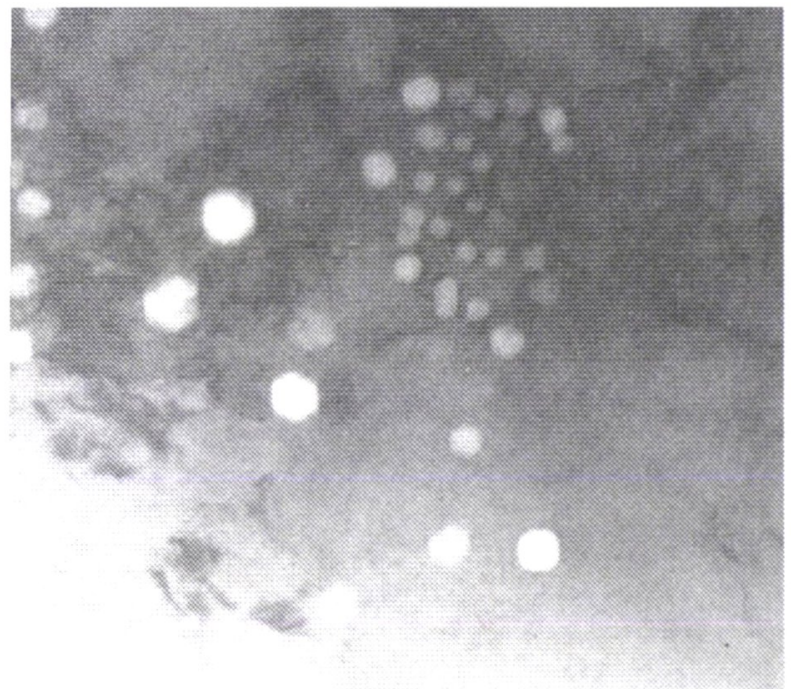

\section{Jürgen Gegner, Andreas Öchsner, Christoph Henninger}

2D- und 3D- Modellierung diskontinuierlicher Dualphasengefüge und äquivalenter Mikrostrukturen aus MikroskopBildserien

2D and 3D Modelling of Discontinuous Dual-Phase Structures and Equivalent Microstructures from Microscope-Made Image Series 564

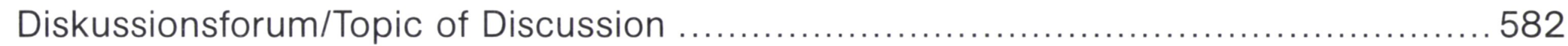

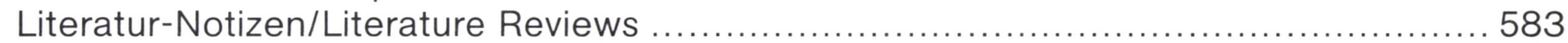

Heitere Metallographie/Humorous Metallography ..................................... 584

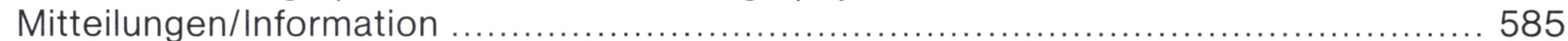

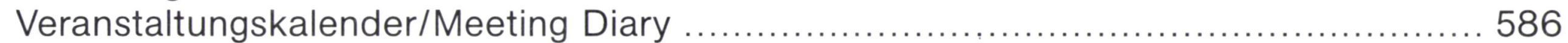




\section{Praktische Metallographie \\ Practical Metallography}

\section{Gründer/Founders}

Günter Petzow

Gerhard Reinacher $†$

Charlotte Wachau $\dagger$

Herausgeber/Editor

Prof. Dr. G. Petzow

Schriftleiter

Editor in charge

Prof. Dr.-Ing. F. Mücklich

Universität des Saarlandes

Lehrstuhl für Funktionswerkstoffe

Postfach 151150

D-66041 Saarbrücken

Telefon: +49/681 302-2048

Telefax: +49/681 302-4876

E-Mail:pm-editor@matsci.uni-sb.de

\section{Redaktion / Editor}

Dipl.-Ing. S. Mücklich

Zöblitzer Str. 10

D-09125 Chemnitz

Telefon: $+49 / 371 / 531-5384$

Telefax: $+49 / 371 / 531-6179$

E-Mail: silke.muecklich@mb.tuchemnitz.de
Wissenschaftlicher Beirat/Editorial Board

Dr. C. Bagnall, MCS Associates Inc., Greensburg, PA (USA

Dr. E. Bischoff, MPI für Metallforschung, Stuttgart

C. Bochert, Buehler $\mathrm{GmbH}$, Düsseldorf

Prof. Dr. H.-E. Bühler, RWTH Aachen

V. Dietl, Lette Verein Berlin

Dr. G. Elssner, MPI für Metallforschung, Stuttgart

Prof. Dr. H.E. Exner, TU Darmstadt

Prof. Dr. M. Göken, Friedrich-Alexander-Univ., Erlangen-Nürnberg

Prof. Dr. E. Hornbogen, Ruhr-Universität Bochum

Prof. Dr. F. Jeglitsch, Montanuniversität Leoben

Prof. Dr. C.-K. Kim, KUT, Korea

Dr. H.-J. Klaar, RWTH Aachen

Prof. Dr. A. Kneissl, Montanuniversität Leoben

Dr. W.-U. Kopp, Daisendorf

Dr. J. Paul, Leica Vertrieb GmbH, Bensheim

Prof. Dr. M. Pohl, Ruhr-Universität Bochum

Prof. Dr. P.D. Portella, BAM, Berlin

Prof. Dr. Schmitt-Thomas, IST, München

Prof. Dr. G. Schneider, Bosch, Stuttgart

U. Täffner, MPI für Metallforschung, Stuttgart

Dr. J. Trempler, Martin-Luther-Univ. Halle-Wittenberg

Prof. Dr. H.-H. Uchida, Tokai Univ., Hiratsuka, Kanagawe

G. Vander Voort, Buehler Ltd., Illinois

Prof. Dr. B. Wielage, TU Chemnitz

Dr. H.-J. Wieland, Verein Dt. Eisenhüttenleute, Düsseldor
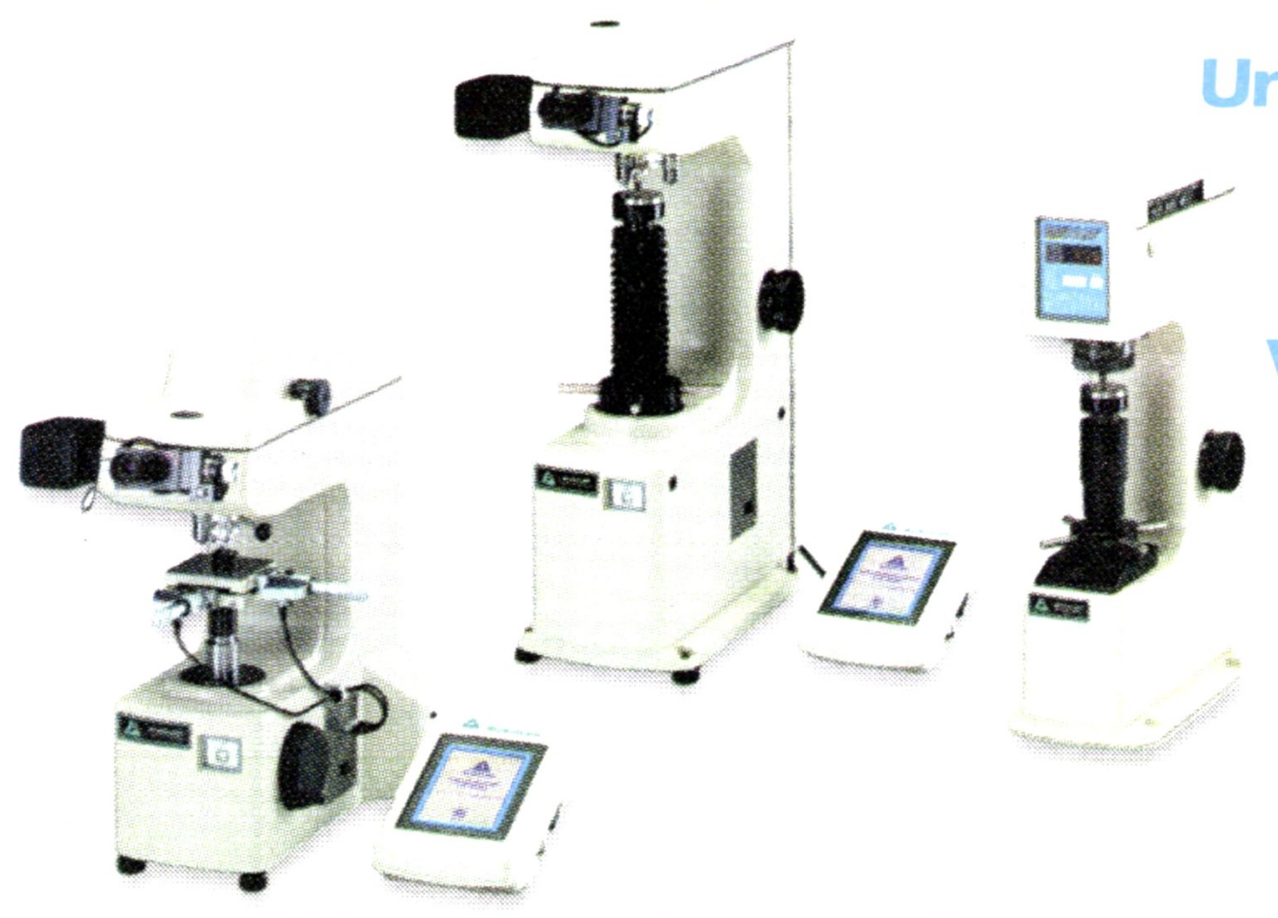

Unsere alktuellen Informationen finden Sie im Internet nur einen Mausklick entfernt! wwMrbuehler-metde
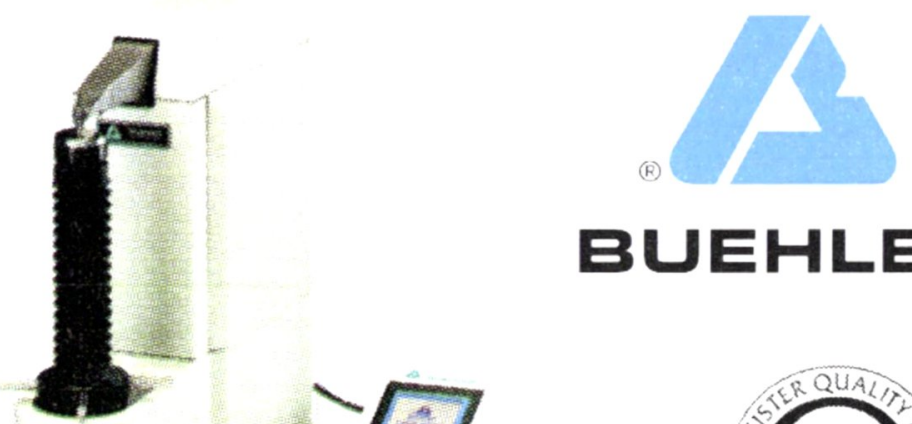

BUEHLER
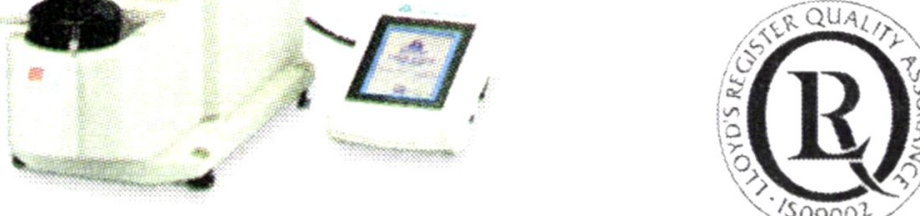
Reg.-Nr. 207017 